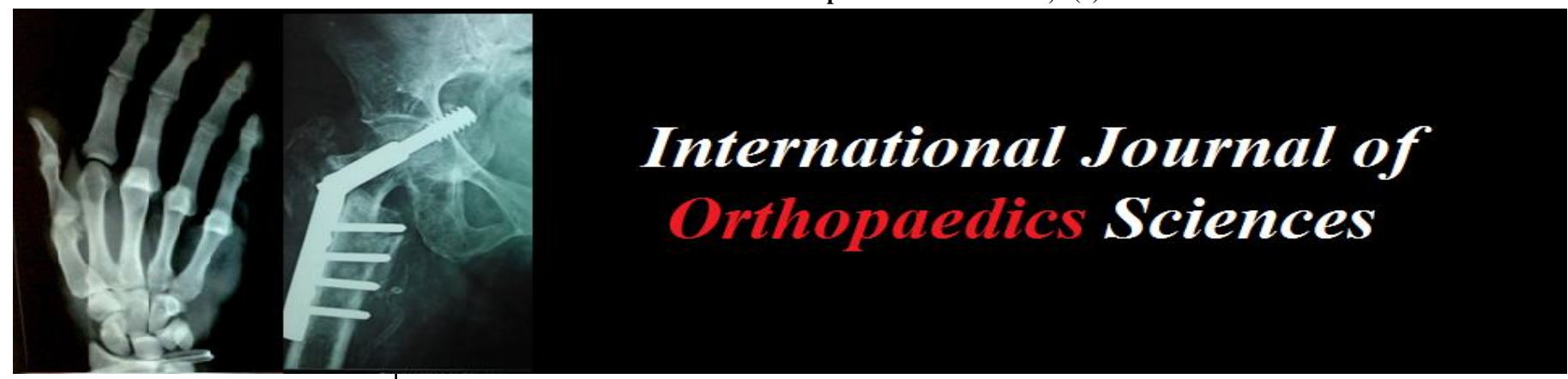

ISSN: $2395-1958$

IJOS 2019; 5(2): 1129-1133

(C) 2019 IJOS

www.orthopaper.com

Received: 18-02-2019

Accepted: 20-03-2019

Dr. A Manikandarajan

Assistant Professor, Department of Orthopaedics, Rajah Muthiah

Medical College, Chidambaram,

Tamil Nadu, India

Dr. D Ganesh

Post Graduate, Department of Orthopaedics, Rajah Muthiah Medical College, Chidambaram, Tamil Nadu, India

Correspondence

Dr. A Manikandarajan

Assistant Professor, Department of Orthopaedics, Rajah Muthiah Medical College, Chidambaram, Tamil Nadu, India

\section{Comparative study of non operative management with primary anatomical locking plating of middle third displaced clavicle fractures - randomised clinical trial}

\section{Dr. A Manikandarajan and Dr. D Ganesh}

DOI: https://doi.org/10.22271/ortho.2019.v5.i2q.1492

\section{Abstract}

Background: Current studies have proven increased prevalence of symptomatic non unions and mal union after non operative management of displaced fractures of mid shaft clavicle. We need to compare outcome and complications between non operative management and primary anatomical locking plating of displaced middle third clavicular fractures.

Methods: In a prospective clinical trial 110 patients with middle third displaced clavicle fractures were randomized to either treatment with primary anatomical locking plate fixation (63) [group 1] or non operative management with sling (47) [group 2]. Outcome was based on standard clinical follow up, constant shoulder score, Disability of the Arm, Shoulder, and Hand (DASH) score and plain radiographs. 85 patients completed lyear of follow up.

Between the groups with relation to demography, mechanism of injury, associated injuries, injury severity score, fracture pattern, there were no difference.

Results: In group 1, there was a significant improvement in constant shoulder score and DASH score at all time-points. ( $\mathrm{p}=0.001$ and $\mathrm{p}<0.01$ respectively). Mean duration for union was 16.0 weeks in 1 st group and 28.0 weeks in group 2 . There were 2 non unions in the group 1 compared with six in the group 2 .

Symptomatic malunion developed in 8 patients in the group 2 and nil in the group 1. Almost complications in the group 1 were hardware-related (patients had irritation, prominent hardware, wound infection, and mechanical failure). At twelve months of the injury, the patients in the group 1 were satisfied with appearance of the shoulder and in general than were those in group 2.

Conclusion: fixation of a displaced clavicle fractures of middle third shaft with anatomical locking plate results in good functional outcome and a lower rate of complications on comparing with nonoperative treatment at 12 months of follow-up. Hardware elimination remains the most customary reason for second surgery in the group 1 . This study supports primary fixation with precontoured locking plate of well displaced middle third fractures of clavicle in active young patients.

Keywords: Clavicle, anatomical locking plate, DASH score, constant shoulder score

\section{Introduction}

Clavicle fractures are not uncommon injuries, accounting for $2.6 \%$ of all fractures 1 , and they occur commonly in active young persons. Middle third fractures account for approximately $80 \%$ of all fractures of clavicle and they have been traditionally treated with a sling, even when displaced ${ }^{[1]}$.

This treatment strategy was based on prior reports that suggested that clavicle nonunion was very rare, with a prevalence of five nonunions in 567 patients in one series and four nonunions in 2236 patients in another. Clavicular malunion was described as being of radiographic curiosity only, and not of clinical importance1-4. However, newer studies of well displaced middle third fractures of clavicle have shown a non union of $15 \%$ ( 8 of 52 patients) in one series as well as a rate of unsatisfactory patient-oriented outcomes of thirty one \% (16 of 52 patients) in one report and thirty two\% (22 of 68 patients) in another, which are higher rates than the previous reports 5-7. 


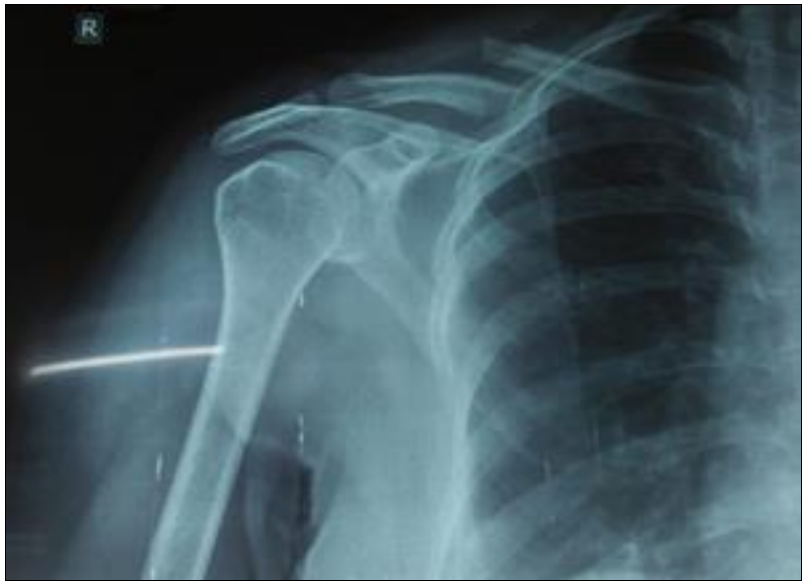

Fig 1: Anteroposterior radiograph of a displaced midshaft clavicular fracture. Note the difference in diameter of the clavicular shaft of the proximal and distal fragments at the fracture site, suggesting that a substantial degree of rotation has occurred.

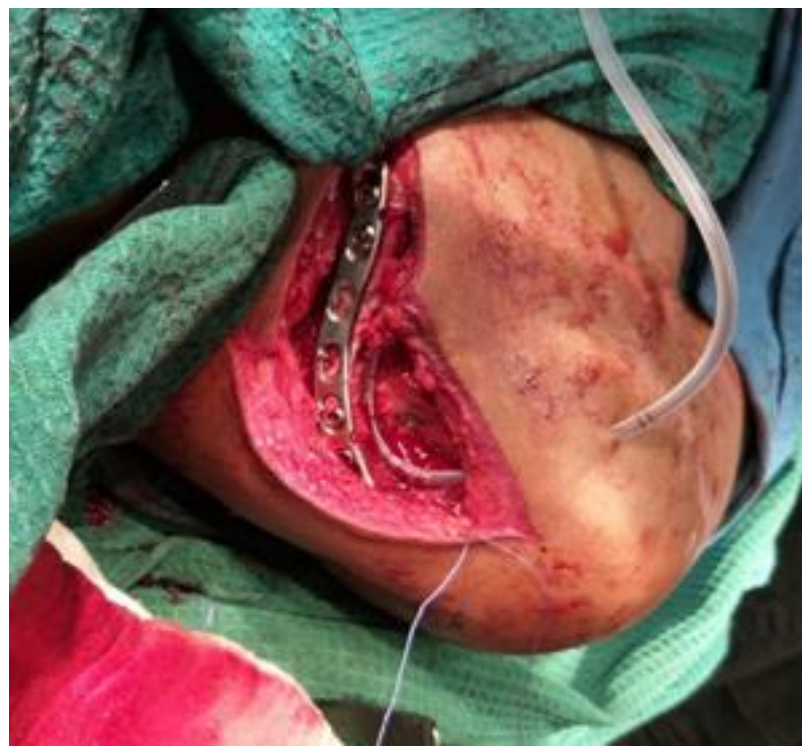

Fig 2: Intraoperative photograph of open reduction and internal fixation of a displaced mid shaft clavicular fracture with a contoured small-fragment plate.

Moreover, malunion of clavicle has currently been described by many authorities as a distinct entity clinically with characteristic radiographic and clinical features. While it is recently accepted that the outcome of closed treatment are much inferior to those described in early reports, operative intervention has not been shown to be superior ${ }^{[2]}$.

Numerous recent studies about the primary internal fixation for middle third displaced fractures of clavicle have noted a high rate of union with minimal complication rate. However, no study prospectively compared plating with sling in a randomized fashion, considered to be the gold standard of comparative studies. A recent meta-analysis of on displaced middle third fractures of clavicle described a reduced nonunion rate after primary fixation with plate (2\%) compared with nonoperative care $(15 \%)$, a relative risk reduction of $86 \%$ (95\% confidence interval, $71 \%$ to $93 \%)^{[3]}$.

The aim of the present, prospective, RCT was to compare outcomes after nonoperative treatment with those after operative treatment of completely displaced middle third fractures of clavicle ${ }^{[4]}$.

\section{Materials and Methods}

This was a, prospective, randomized clinical trial. Eligible patients were randomized to Group 2 nonoperative or Group 1 operative care for displaced clavicle fractures with no cortical contact.

The primary outcome was measured by the (DASH) score, while secondary outcome was measured by the Constant score, rate of union, and rates of complication. The null hypothesis sates that there was no difference between the two groups with respect to outcome scores.

\section{Inclusion Criteria}

(1) a completely displaced middle one-third fracture of the clavicle, (2) a fracture in the middle third of the clavicle (a fracture where plate fixation with a atleast 3 screws in both proximal and distal fragment), (3) age 16 to 60 years, (4) no contraindications to general anesthesia, and (5) provided informed consent.

\section{Exclusion Criteria}

(1)age < 16 years or >60 years, (2) a fracture in the proximal or distal third of the clavicle, (3) a pathological and open fracture, (4) a fracture > 4 weeks old (5) an associated neurovascular injury, (6) an associated head injury), (7) an upper extremity fracture distally (8) an inability to followup (9) contraindication to surgery and/or anesthesia (such as heart disease, renal failure, or active chemotherapy), and (10) a lack of consent.

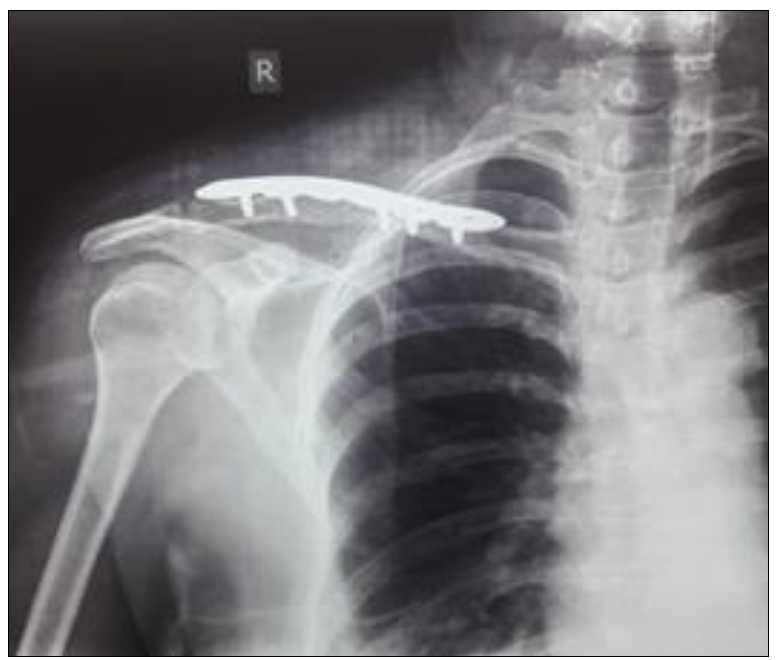

Fig 3: Postoperative radiograph after open reduction and internal fixation of the displaced midshaft clavicular fracture.

\section{Sample Size Calculation}

Before beginning of the study, a power analysis was performed. The choice of sample size was made based on the primary outcome of shoulder function scores. Assuming a beta error of .05 and a power of .8 , it was anticipated that sixty patients would be required in each group in order to demonstrate a $15 \%$ difference in the shoulder scores between the two groups.

\section{Randomization}

In the fracture room, the orthopaedic resident identified the patient who are fit for the study and protocol was introduced. The patient then examined by the nurse and the study was explained, and consent was obtained. Once consent was obtained, randomization was done.

\section{Nonoperative Care}

Patients received a standard sling for six weeks. Following union, physiotherapy for strengthening was prescribed. 


\section{Operative Technique}

Patients randomized to operative group were operated within 28 days. Prophylactic antibiotics were given. Under a general anesthesia, the patient was in a beach-chair position. The shoulder was prepared and draped, and an incision was made over the fracture site. Larger branches of the supraclavicular nerves were protected throughout the procedure; smaller branches were sacrificed at the surgeon's discretion ${ }^{[5]}$.

The fracture site was identified, and the fracture was reduced and fixed with a anatomical locking plate superiorily, with minimum of three screws in the main proximal and distal fragments. Comminuted fragments were secured with lag screws if possible, with care being taken to preserve softtissue attachments, and a longer plate was selected to maintain a minimum of three screws in the primary proximal and distal fragments. Followed by skin closure. No drains were used ${ }^{[6]}$. A sling was given for comfort for 7 to 10 days, and then active range of-motion exercises were performed at home. When radiographic union and no pain or motion on stressing of the fracture was evident, six weeks typically, strengthening exercises was allowed, with a return to normal activities at 3 months. However, as the patients were predominantly young men, many returned to and occupational activities earlier than recommended ${ }^{[7]}$.

\section{Assessment}

Following enrolment in the study, the patients were seen at six weeks and at three, six, and twelve months. Assessment included standardized clinical evaluation and completion of the Constant score and DASH score. Both an anteroposterior and a $20^{\circ}$ cephalad radiograph were made for each patient. Radiographic union was defined as complete cortical bridging between the two fragments on both the views ${ }^{[8]}$.

\section{Adverse Events and/or Complications}

An adverse event was defined as any event that necessitated another procedure or additional medical treatment. Nonunion was defined as the absence of radiographic union with pain and motion at the fracture site at 12 months.

Radiographic malunion, was common in the nonoperative group. symptoms like weakness, fatigability, pain with overhead activity, neurologic symptoms, and shoulder asymmetry were common with malunion. The Pearson correlation coefficient was used for comparison of the DASH scores at one year Results one hundred and thirty-three patients with 133 fractures were entered in the study between April 2015 and December 2018. Sixty-three patients were randomized to the operative group and forty seven to the nonoperative group ${ }^{[9]}$.

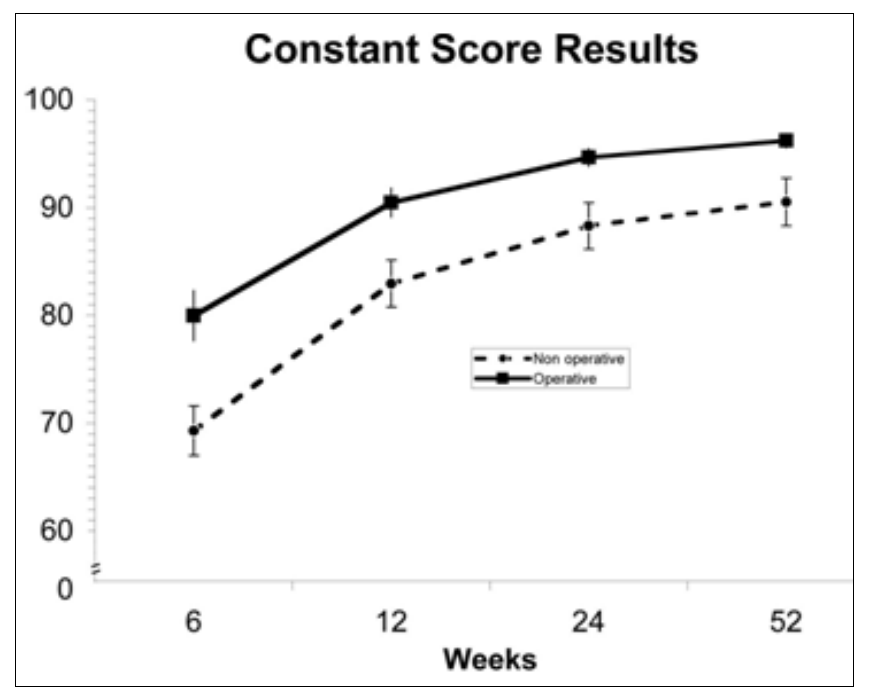

Fig 4: Graphic analysis comparing the mean Constant shoulder scores in the operative and nonoperative groups at six, twelve, twenty-four, and fifty-two weeks of follow-up. The values are improved for the operative group at each time-point $(p<0.01$ for all).

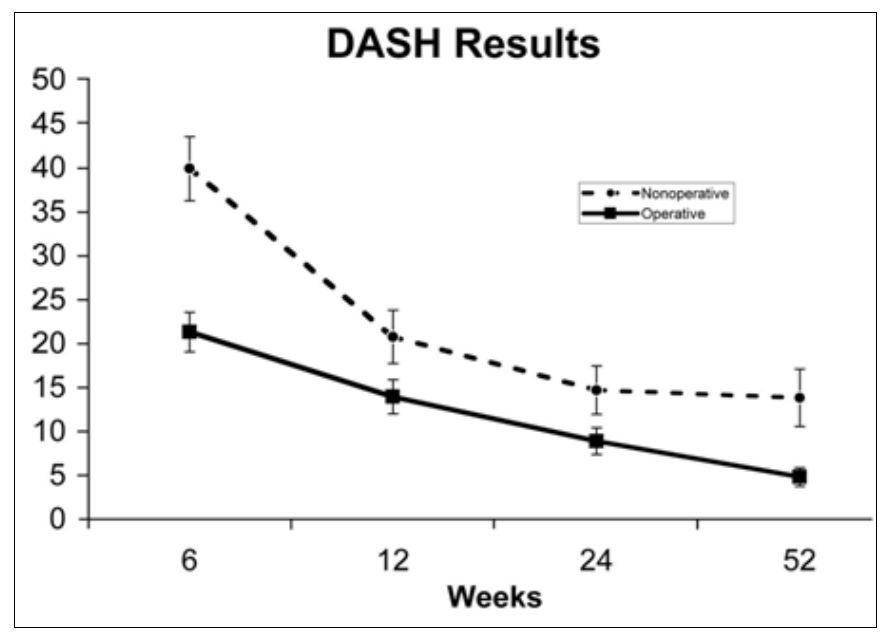

Fig 5: Graphic analysis comparing the mean Disability of the Arm, Shoulder and Hand (DASH) scores in the operative and nonoperative groups at six, twelve, twenty-four, and fifty-two weeks of follow- up. The DASH is a disability score where a "perfect" extremity would typically score 0 (mean values for a "normal" extremity range from 4 to 8). Values are worse in the nonoperative group at each time-point (p $<0.01$ at six weeks, $\mathrm{p}=0.04$ at twelve weeks, $\mathrm{p}=0.05$ at twenty-four weeks, and $\mathrm{p}<0.01$ at fifty-two weeks).

Table 1: Demographic Data on the Patients and Characteristics of the Fractures

\begin{tabular}{|c|c|c|c|}
\hline Parameter & Operative Group (N = 62) & Nonoperative Group (N = 49) & P Value \\
\hline Male & 53 & 34 & 0.062 \\
\hline Female & 9 & 15 & 0.062 \\
\hline Mean age $(y r)$ & 33.5 & 33.5 & 0.644 \\
\hline (Mean) height $(\mathrm{cm})$ & 173.9 & 167.0 & 0.213 \\
\hline Mean Injury Severity Score & 5.8 & 7.2 & 0.232 \\
\hline Associated fractures & 8 & 6 & 0.756 \\
\hline
\end{tabular}




\begin{tabular}{|c|c|c|c|}
\hline Dominant arm & 26 & 20 & 0.561 \\
\hline Smokers & 19 & 16 & 0.624 \\
\hline Mean fracture angulation $(\mathrm{deg})$ & 11.9 & 12.7 & 0.563 \\
\hline Mean fracture shortening $(\mathrm{mm})$ & 15.7 & 14.3 & 0.209 \\
\hline Mean total fracture displacement $(\mathrm{mm})$ & 20.1 & 19.3 & 0.478 \\
\hline Mechanism of injury (no. of patients) & & & $>0.05$ for \\
\hline Fall & 9 & 7 & \\
\hline Sports & 9 & 6 & \\
\hline Motor-vehicle or motorcycle accident & 16 & 14 & \\
\hline Skiing or snowboarding & 7 & 10 & \\
\hline Bicycling & 15 & 8 & \\
\hline Other & 6 & 4 & \\
\hline
\end{tabular}

\section{Results}

Both were followed in their original groups. 2 in the non operative group were died in a motor-vehicle accident, and 14 were lost to follow-up by 12 months. 4 in the operative group were lost to follow-up at 12 months. Constant Shoulder Scores The group 2 had significantly good Constant shoulder scores at all time-points $(\mathrm{p}<0.01)$ The group 2 had significantly lower DASH scores at all time-points persisting to 12 months $(\mathrm{p}<0.01)$.

\section{Patient Satisfaction}

At each assessment, patients were asked "Are you satisfied with your shoulder?" At each assessment, patients in the operated were likely to reply "yes" to this question, Range of motion was well maintained, and there were no significant differences in measured range of motion between the two groups. No patient lost $>10^{\circ}$ of motion in any plane. Fracture Union the mean was 16.0 weeks in the group 2 and 28.0 weeks in the group 1 for union $(p=0.001)$.

Table 2: Complications

\begin{tabular}{|c|c|c|c|}
\hline Adverse Event & Operative Group (N = 62) & Nonoperative Group (N = 49) & P Value \\
\hline Nonunion & $2^{*}$ & 7 & 0.042 \\
\hline Malunion requiring further treatment & 0 & 9 & 0.001 \\
\hline Wound infection and/or dehiscence & 3 & 0 & 0.253 \\
\hline Hardware irritation requiring removal & 5 & 0 & 0.065 \\
\hline Complex regional pain syndrome & 0 & 1 & 0.441 \\
\hline Surgery for impending open fracture & 0 & 2 & 0.192 \\
\hline Transient brachial plexus symptoms & 8 & 7 & 0.690 \\
\hline Abnormality of the acromioclavicular or & 2 & 3 & 0.653 \\
\hline sternoclavicular joint & 1 & 0 & \\
\hline Early mechanical failure & 2 & 2 & 1.000 \\
\hline Other & $23(37 \%)$ & $31(63 \%)$ & 0.784 \\
\hline Total & \multicolumn{2}{|c|}{0} & 0.008 \\
\hline
\end{tabular}

*One patient who was randomized to operative fixation declined surgery. He had a nonunion of the fracture at one year. According to the "in- tention-to-treat" principle, the complication was included in the operative group as a nonunion. See text.

Nonunion occurred in two patients in the group 2 and in seven in the group 1. Adverse Events and/or Complications, including nonunion and symptomatic malunion, were more in the nonoperative group. Com plications in the fixation group were hardware related. Wound infection and dehiscence following fixation of the clavicle another feared complication.
We had two such patients managed with appropriate antibiotics and wound care. Once union had occurred, all underwent implant removal and debridement with resolution of the infection. Patients in the operative group were satisfied with the appearance of the shoulder $(\mathrm{p}=0.001)$.

Table 3: Appearance of Shoulder

\begin{tabular}{|c|c|c|c|}
\hline Condition & Operative Group (N = 62) & Nonoperative Group (N = 49) & P Value \\
\hline "Droopy" shoulder & 0 & 10 & 0.001 \\
\hline Bump and/or asymmetry & 0 & 22 & 0.001 \\
\hline Scar & 3 & 0 & 0.253 \\
\hline Sensitive and/or painful fracture site & 9 & 10 & 0.891 \\
\hline Hardware irritation and/or prominence & 11 & 0 & 0.001 \\
\hline Incisional numbness & 18 & 0 & 0.001 \\
\hline Satisfaction with appearance & 52 & 26 & 0.001 \\
\hline
\end{tabular}

Neer found nonunion in three of 2237 patients with middle third fractures treated non operatively, while Rowe found nonunion in five of 567 clavicular fractures, Robinson et al. described a series of 869 patients with clavicle fractures, 582 had a middle third fracture.

They found a higher rates of nonunion for the displaced, comminuted middle third fractures. Similarly, in a study, Hill et al. also reported high rates of non union. They concluded that displacement of the fracture fragments by $>2 \mathrm{~cm}$ was associated with an unsatisfactory result. McKee et al. described the typical inferior, shortened, and anteriorly rotated position of the distal fragment in clavicular malunion and the symptoms that resulted from it. Our study found (in the nonoperative group) a direct relationship between increased displacement and a worse DASH score. Survivors showed a substantial level of residual problem in the involved shoulder. 


\section{Discussion}

Most studies have found a correlation between fracture comminution (and displacement) and poor outcome, and these fracture features are associated with higher energy trauma. With newer implants, good antibiotics, and good soft-tissue handling, plating has become the effective technique ${ }^{[10]}$. Modern studies on plating of middle third displaced fractures of clavicle have described successful rates of union from $94 \%$ to $100 \%$ and very low infection rates and complications ${ }^{[11-12]}$. Complications expected were brachial plexus palsy, vascular injury, or pneumothorax; hardware removal was the most common reason for reintervention ${ }^{[13]}$.

Patients were more satisfied with the shoulder (and its appearance) following operative intervention. While we found that our findings are applicable only to a subset of clavicle injuries, our study supports primary fixation with precontoured anatomical locking plate of completely displaced middle third fractures of clavicle in active young adults ${ }^{[14-15]}$.

\section{References}

1. Neer C. Fractures of the clavicle. In: Rockwood CA Jr, Green DP, editors. Fractures in adults. 2nd ed. Philadelphia: Lippincott, 1984, 707-13.

2. Crenshaw AH. Fractures of the shoulder girdle, arm and forearm. In: Crenshaw AH, editor. Campbell's operative orthopaedics. 8th ed. St. Louis: Mosby Year Book, 1992, 989-1053.

3. Neer CS. 2nd. Nonunion of the clavicle. JAMA. 1960; 172:1006-11.

4. Rowe CR. An atlas of anatomy and treatment of midclavicular fractures. Clin Orthop Relat Res. 1968; 58:29-42.

5. McKee MD, Schemitsch EH, Stephen DJ, Kreder HJ, Yoo D, Harrington J. Functional outcome following clavicle fractures in polytrauma patients [abstract]. J Trauma. 1999; 47:616.

6. Hill JM, McGuire MH, Crosby LA. Closed treatment of displaced middle-third fractures of the clavicle gives poor results. J Bone Joint Surg Br. 1997; 79:537-9.

7. Nordqvist A, Petersson CJ, Redlund-Johnell I. Midclavicle fractures in adults: end result study after conservative treatment. J Orthop Trauma. 1998; 12:5726.

8. McKee MD, Wild LM, Schemitsch EH. Midshaft malunions of the clavicle. J Bone Joint Surg Am. 2003; 85:790-7.

9. Basamania CJ. Claviculoplasty and intramedullary fixation of malunited, shortened clavicular fractures. J Shoulder Elbow Surg. 1999; 8:540.

10. Bosch U, Skutek M, Peters G, Tscherne H. Extension osteotomy in malunited clavicular fractures. J Shoulder Elbow Surg. 1998; 7:402-5.

11. Chan KY, Jupiter JB, Leffert RD, Marti R. Clavicle malunion. J Shoulder Elbow Surg. 1999; 8:287-90.

12. Kuhn JE. Symptomatic malunions of the middle clavicle. J Shoulder Elbow Surg. 1999; 8:539.

13. Robinson CM. Fractures of the clavicle in the adult. Epidemiology and classifi- cation. J Bone Joint Surg Br. 1998; 80:476-84.

14. Zlowodzki M, Zelle BA, Cole PA, Jeray K, McKee MD. Evidence-Based Ortho- paedic Trauma Working Group. Treatment of midshaft clavicle fractures: systemic review of 2144 fractures: on behalf of the Evidence-Based Orthopaedic Trauma Working Group. J Orthop Trauma.
2005; 19:504-7.

15. Poigenfurst J, Rappold G, Fischer W. Plating of fresh clavicular fractures: results of 122 operations. Injury. 1992; 23:237-41. 